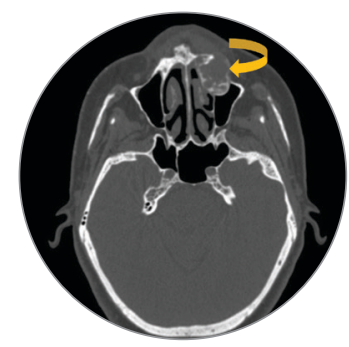

$\sum$

Palabras clave (DeCS)
Osteítis fibrosa quística
Neoplasias de las
paratiroides
Hiperparatiroidismo
primario
Radiografía

\section{Key words (MeSH)}

Osteitis fibrosa cystica

Parathyroid neoplasms

Primary

hyperparathyroidism

Radiography
'Radióloga, Hospital Escuela Universitario. Hospital Escuela Universitario. Tegucigalpa, Honduras.

2Radióloga, posgrado de Radiología. Universidad Nacional Autónoma de Honduras (UNAH).

${ }^{3}$ Radiólogo, posgrado de Radiología. Universidad Nacional Autónoma de Honduras (UNAH).

${ }^{4}$ Radiólogo intervencionista. Hospital Escuela Universitario (HEU). Tegucigalpa, Honduras

${ }^{5}$ Residente de tercer año, posgrado de Radiología. Universidad Nacional Autónoma de Honduras (UNAH)

Hospital Escuela Universitario. Tegucigalpa, Francisco Morazán, Honduras.

\title{
Tumor pardo multifocal como manifestación inicial de carcinoma paratiroideo. Presentación de caso
}

\author{
Multifocal Brown Tumor as A Manifestation Of Primary Parathyroid \\ Carcinoma. A Case Report
}

María Berenice Reyes ${ }^{1}$ Silvia Lissett Espinoza Alvarado² Didier Armando Robles López ${ }^{3}$ Carlos Rivera Argeñal ${ }^{4}$ Yaritza Turcios ${ }^{5}$

\section{Resumen}

El carcinoma de paratiroides es una causa excepcional de hiperparatiroidismo primario. Los tumores pardos se desarrollan como manifestaciones esqueléticas de hiperparatiroidismo primario en el contexto de una enfermedad avanzada. Son lesiones óseas líticas, altamente vasculares con un proceso celular reparador en lugar de un proceso neoplásico. Pueden identificarse en las formas secundarias de la enfermedad; sin embargo, son más frecuentes en el hiperparatiroidismo primario. Se presenta el caso de múltiples tumores pardos secundarios a un carcinoma de paratiroides. La manifestación inicial del hiperparatiroidismo primario fue una fractura patológica secundaria a tumor pardo asociado con hipercalcemia y niveles elevados de hormona paratiroidea (PTH), lo cual es infrecuente debido a que en las últimas décadas la incorporación del calcio sérico en las pruebas de rutina de laboratorio detecta esta enfermedad en estadios asintomáticos o mínimamente sintomáticos. Por ultrasonido se detectó lesión sólida vascularizada en sitio anatómico de paratiroides inferior izquierda y nefrocalcinosis. Se sometió a resección quirúrgica de la lesión en hemicuello izquierdo y la biopsia reportó carcinoma de paratiroides. Los tumores pardos son lesiones no neoplásicas que no tienen potencial maligno por lo que se consideran granulomas reparadores.

\section{Summary}

Parathyroid carcinoma is an exceptional cause of primary hyperparathyroidism. Brown tumors develop as skeletal manifestations of primary hyperparathyroidism in the context of advanced disease. They are highly vascular, Iytic bone lesions with a reparative cellular process instead of a neoplastic process. They can be identified in the secondary forms of the disease, however, they are more frequent in primary hyperparathyroidism. We present a case of multiple brown tumors secondary to parathyroid carcinoma. The initial manifestation of primary hyperparathyroidism was a pathological fracture secondary to brown tumor associated with hypercalcemia and elevated levels of parathyroid hormone (PTH), which is rare due to the fact that in recent decades the incorporation of serum calcium in routine laboratory tests detects this disease in asymptomatic or minimally symptomatic stages. Ultrasound detected a vascularized solid lesion in the anatomical site of the left lower parathyroid and nephrocalcinosis. The lesion was surgically resected in the left hemicolumn and the biopsy reported parathyroid carcinoma. Brown tumors are non-neoplastic lesions that do not have malignant potential and are therefore considered repairing granulomas.

\section{Introducción}

En 1864, Gerhard Engel describió por primera vez el tumor pardo y en 1925 Mandl lo asoció con el hiperparatiroidismo. El nombre de tumor pardo se originó por su apariencia histológica macroscópica, ya que la masa parduzca estaba conformada por una combinación de microfracturas, recurrentes en varias etapas de remodelación, con sangre, hemosiderina, tejido fibroso y conjuntivo. Aunque se llamen tumores, no lo son; según este autor, los tumores pardos no son el resultado de un proceso neoplásico. Son lesiones óseas focales como consecuencia de la remodelación ósea por hiperparatiroidismo o síndrome paraneoplásico (1).

El aumento de paratohormona puede ser resultado de hiperparatiroidismo primario, el cual, en un $80-90 \%$ es secundario a un adenoma paratiroideo, $5-10 \%$ es producido por enfermedad multiglandular y en menos del $1 \%$ por el carcinoma paratiroideo. También puede ocasionarlo un hiperparatiroidismo secundario, como insuficiencia renal crónica y malabsorción intestinal, o hiperparatiroidismo terciario, como funcionamiento autónomo de las paratiroides en casos de hiperparatiroidismo de larga evolución (2). 
El hiperparatiroidismo primario predomina en las mujeres con una relación 3:1 y su prevalencia aumenta con la edad de $0,5 \%$ en mujeres de 50 a 59 años a 1,75 \% en mujeres de 70 a 75 años. En países occidentales, la sintomatología del hiperparatiroidismo primario es muy leve y su progresión es muy lenta. Los principales efectos se manifiestan en el sistema renal y óseo. El 75-80 \% de los pacientes son asintomáticos; sin embargo, pueden tener síntomas inespecíficos como fatiga, debilidad, parestesias, afectaciones digestivas y alteraciones mentales leves. En muchos de estos pacientes se evidencia que la fatiga y la debilidad eran síntomas de la enfermedad después de la paratiroidectomía, cuando los síntomas se resuelven (3).

Las manifestaciones esqueléticas del hiperparatiroidismo primario son la principal causa de morbilidad asociada a esta enfermedad. Los hallazgos radiológicos óseos característicos son la reabsorción subperióstica de la cortical ósea en múltiples localizaciones — más temprana en la cara radial de las falanges medias del segundo y tercer dedo-, la osteopenia generalizada o yuxtaarticular y los tumores pardos $(4,5)$.

El tumor pardo u osteítis fibrosa quística se manifiesta como una lesión lítica de bordes definidos, caracterizada por cúmulos focales de tejido fibroso y células gigantes en un estroma hemorrágico muy vascularizado $(6,7)$, por lo general son multiloculares, bien delimitados y presentan adelgazamiento de las corticales óseas como resultado de un proceso celular de reparación (8).

De hecho, algunas de las lesiones osteolíticas podrían confundirse con metástasis óseas, con un quiste óseo solitario, un quiste óseo aneurismático, un tumor de células gigantes o un granuloma reparador de células gigantes. En los tumores pardos múltiples, el diagnóstico diferencial incluye: metástasis osteolíticas, mieloma múltiple, quistes óseos múltiples, etc. Es el margen esclerótico lo que excluye la metástasis (9).

Pueden cursar con edema, fracturas patológicas y dolor óseo en el sistema esquelético. Esto se produce por un aumento de la reabsorción osteoclástica del hueso debida a un incremento de la paratohormona en sangre. Afectan principalmente huesos largos, costillas, pelvis, maxilar, mandíbula, cráneo e incluso vértebras (10).

El tratamiento primario de los tumores pardos es la extirpación quirúrgica de la glándula paratiroidea, ya que la mayoría involucionan en un tiempo de 6 meses a 5 años. Los niveles séricos normales de paratohormona, calcio, fósforo y el aumento de la masa ósea en el área tumoral son indicadores de éxito del tratamiento. La resección quirúrgica ósea mediante curetaje y enucleación está indicada en lesiones quísticas extensas con gran destrucción ósea, que no involucionan debido a que en estas la probabilidad de mineralización es baja una vez tratada la causa de la hipercalcemia (4).

El carcinoma de paratiroides es una neoplasia maligna endocrina poco común, descrita por primera vez por De Quevain, en 1909 (6). El comportamiento de esta patología se ha descrito como de evolución lenta, pero progresiva, el $95 \%$ son funcionantes. Infiltra localmente, puede diseminarse a ganglios regionales y presentar, eventualmente, metástasis pulmonares (11).

La incidencia del carcinoma de paratiroides se describe como inferior al $1 \%$ de los casos de hiperparatiroidismo primario (12).

La patogenia del carcinoma de paratiroides es desconocida. Puede ser esporádico o aparecer en el contexto de un síndrome endocrino genético, como en el síndrome de hiperparatiroidismo/tumor de la mandíbula (HPTJT), neoplasia endocrina múltiple tipo 1 (MEN1), tipo 2A (MEN2A) e hiperparatiroidismo familiar aislado (FIHP) (13).
Se manifiesta en una edad promedio de 40 a 55 años, con igual distribución en los sexos. En la estadificación se clasifica como enfermedad localizada, metastásica y recurrente (14).

El tejido paratiroideo generalmente está compuesto por células principales y puede tener células oxifílicas, células de transición y células claras. Las células parenquimatosas generalmente se entremezclan con adipocitos en cantidades variables; este tejido adiposo corresponde al 10 a $30 \%$ del volumen glandular. La celularidad de una glándula paratiroidea varía dentro y entre individuos. Generalmente, una glándula paratiroides que pesa más de $40 \mathrm{mg}$ es anormal (15).

Con la evaluación de las características clínicas, de laboratorio y radiográficas, la mayoría de las lesiones paratiroideas se pueden clasificar fácilmente. Sin embargo, el diagnóstico de carcinoma paratiroideo puede ser difícil. Los niveles de calcio y PTH en sangre se encuentran mucho más elevados en el carcinoma que en las causas benignas de hiperparatiroidismo. En el carcinoma paratiroideo metastásico, los principales problemas se derivan de los efectos incontrolados del exceso de PTH y las principales causas de morbilidad y mortalidad son la hipercalcemia y la enfermedad ósea (16).

Los carcinomas paratiroideos son generalmente más grandes que los adenomas, pero puede haber superposición de tamaño. Los carcinomas por lo general se asocian con niveles de calcio sérico más altos que el de los adenomas, pero estos se pueden superponer. Los carcinomas paratiroideos usualmente tienen tasas mitóticas más altas que los adenomas paratiroideos, pero la actividad mitótica también se da en los adenomas. Las mitosis atípicas se ven solo en carcinoma paratiroideo. Los adenomas paratiroideos atípicos tienen algunas características que se ven a menudo en los carcinomas, tales como actividad mitótica, atipia citológica, bandas fibrosas, adherencia a estructuras adyacentes, crecimiento trabecular y células tumorales dentro de la cápsula, pero carecen de invasión o metástasis $(17,18)$.

Hasta la fecha, la invasión vascular patológica, ruptura de la cápsula en estructuras adyacentes al cuello o metástasis regionales y a distancia siguen siendo los criterios para malignidad (19).

Se han descrito varios hallazgos que ayudan a distinguir los adenomas paratiroideos benignos del carcinoma paratiroideo. El adenoma paratiroideo típico suele ser de consistencia blanda, de forma redonda u ovalada y de color marrón rojizo. Por el contrario, el carcinoma paratiroideo se describe con frecuencia como una masa lobulada, firme a pedregosa. En aproximadamente el $50 \%$ de los casos está rodeado por una cápsula densa, fibrosa, de color blanco grisáceo que se adhiere tenazmente a los tejidos adyacentes y dificulta la separación del tumor de las estructuras contiguas. Si hay una infiltración grave de la glándula tiroides adyacente, nervios, músculos o del esófago, o si existen metástasis obvias en ganglios cervicales, el diagnóstico de carcinoma no es difícil. Sin embargo, cualquiera o todos estos hallazgos pueden estar ausentes en el acto operatorio, y el examen patológico por congelación es de poco valor para distinguir la enfermedad benigna de la maligna (20).

Los tumores pardos se caracterizan por su apariencia lítica en la imagen por tomografía y su realce en la gammagrafía ósea (21).

Actualmente, la gammagrafía con Sestamibi-Tc99m se considera una herramienta con mayor sensibilidad (80-100 \%) para detectar tanto la hiperfunción paratiroidea como la existencia de glándulas ectópicas (5).

La radioterapia y la quimioterapia no son efectivas en el manejo del carcinoma paratiroideo. Al paciente se le trata con calcio y vitamina D. Se debe realizar monitoreo estricto en los dos años siguientes a la cirugía, ya 
que la mayoría de las recurrencias ocurren en los primeros 3-4 años. Sin embargo, se han informado recaídas a los 10-15 años. La tasa de supervivencias a los 5 años es de un 50-80 \%. La edad, la cirugía inicial incompleta y el tipo histológico (aneuploide) son factores de peor pronóstico (14).

En pruebas diagnósticas como la tomografía computarizada (TC) o la resonancia magnética $(\mathrm{RM})$, los tumores pardos producen imágenes que en ocasiones simulan lesiones óseas líticas que plantean el diagnóstico diferencial con metástasis de tumores malignos (10).

\section{Presentación del caso}

Paciente femenina de 37 años de edad con historia de poliuria, polidipsia, astenia y estreñimiento, de aproximadamente dos años de evolución, con dolor en miembro inferior izquierdo durante los últimos 4 meses; sufre caída de su propia altura, acompañada de debilidad, edema y limitación funcional de la cadera ipsilateral. Al examen físico se encuentra acortamiento del miembro inferior izquierdo, en rotación externa, con deformidad en el tercio proximal de muslo, no se observan laceraciones, equimosis ni hematomas; presenta dolor a la movilización, con pulsos distales palpables, sin parestesias.

Los exámenes de laboratorio tienen los siguientes resultados: paratohormona, $635 \mathrm{pg} / \mathrm{mL}$; calcio, $14,8 \mathrm{mg} / \mathrm{dL}$; vitamina D, $19 \mathrm{ng} / \mathrm{mL}$; proteína de Bence Jones y marcadores tumorales negativos.

Se realizó una serie ósea radiográfica en la que se aprecian múltiples lesiones líticas intramedulares bien delimitadas, con adelgazamiento de las corticales óseas en el fémur derecho (figura 1a) y una fractura patológica en el tercio proximal de fémur izquierdo (figura $1 b$ ).
Un ultrasonido de abdomen identificó múltiples cálculos en la vesícula biliar e imágenes hiperecoicas, difusas, en la región medular de ambos riñones por nefrocalcinosis (figura 2). Así mismo, imágenes hiperecoicas en la vejiga urinaria.

En el ultrasonido de cuello se identifica en el sitio anatómico de la glándula paratiroides inferior izquierda una lesión hipoecoica, sólida, de bordes definidos, con vascularidad periférica y central, de $3 \times 1,5 \times 1,6 \mathrm{~cm}$, en sus diámetros longitudinal, anteroposterior y transversal con volumen de $3,9 \mathrm{~cm}^{3}$ (figura 3).

En la tomografía computarizada (TC) multidetector de tórax y abdomen simple se evidenciaron lesiones ovaladas y redondas, de bordes definidos, con expansión de las cortical óseas, localizadas en el séptimo arco costal posterior derecho, séptimo y octavo anterior izquierdo, octavo y novenos arcos posteriores bilateralmente (figura 4), en ambas escápulas y huesos ilíacos, en pubis derecho, isquion izquierdo, ala sacra izquierda, trocánter mayor de ambos fémures, cuerpos vertebrales T12, L3, y pedículo vertebral de L2 (figura 5). Estas lesiones son características de tumores pardos. Además, se identificó nefrocalcinosis renal bilateral, imágenes de alta densidad en la región posterior de la vejiga urinaria y múltiples litos en la vesícula biliar.

En TC multidetector de cuello se observaron lesiones de similares características en la pared interna del seno maxilar izquierdo, que comprimen el cornete nasal inferior izquierdo. Además, lesiones líticas de bordes bien definidos en el cuerpo mandibular derecho, paladar duro y en la región intramedular de los cuerpos vertebrales C5 y C6 (figura 6). Posteriormente, se resecó quirúrgicamente la masa, y la biopsia por congelación reveló carcinoma de paratiroides (figura 7).
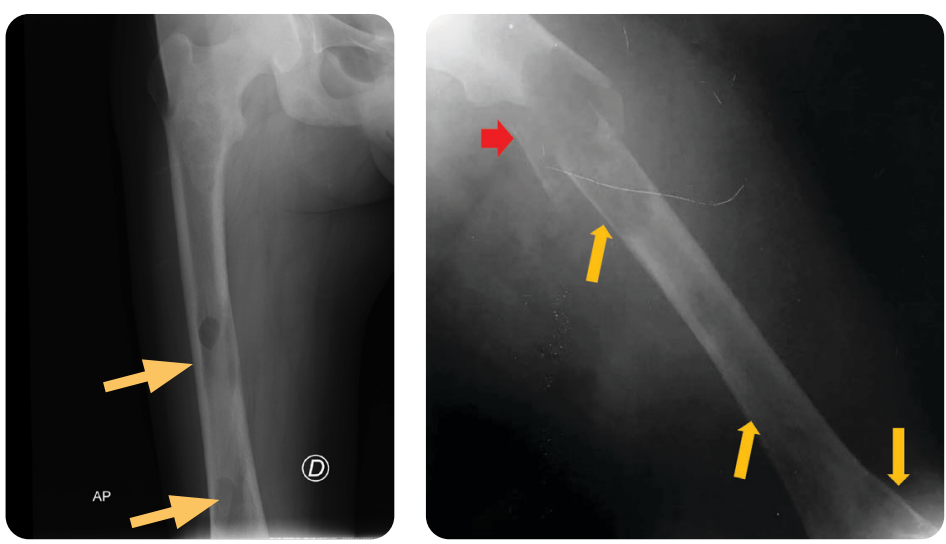

Figura 1. a) Proyección anteroposterior (AP) del fémur derecho: En el tercio medio y distal del fémur se observan dos lesiones ovaladas intramedulares, radiolúcidas, de bordes definidos, sin reacción perióstica (flechas). b) Proyección lateral del fémur izquierdo: Fractura desplazada, multifragmentaria en el tercio proximal del fémur (cabeza de flecha) asociada con lesión osteolítica en la región diafisaria y adelgazamiento de la cortical en el tercio proximal, medial y distal del fémur (flechas).
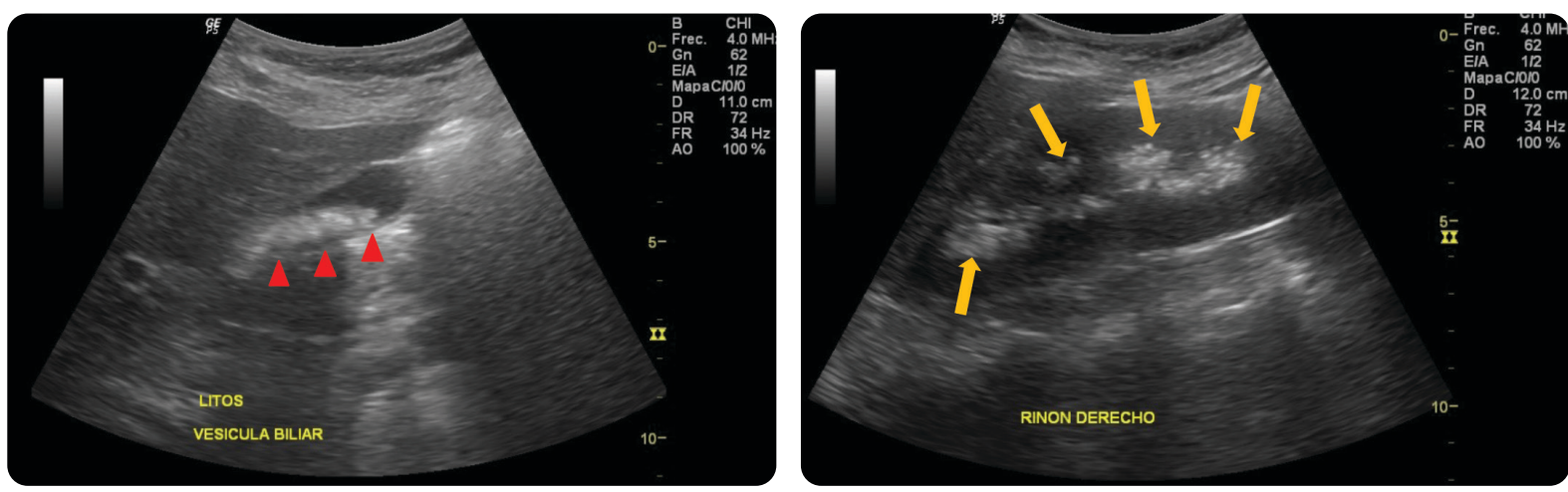

Figura 2. Ultrasonido de abdomen superior. a) Corte longitudinal de la vesícula biliar: múltiples imágenes hiperecoicas con sombra acústica posterior en la vesícula biliar. b) Vista lateral del eje longitudinal del riñón derecho: múltiples imágenes hiperecoicas en la región medular del riñón confinadas en las pirámides renales. 

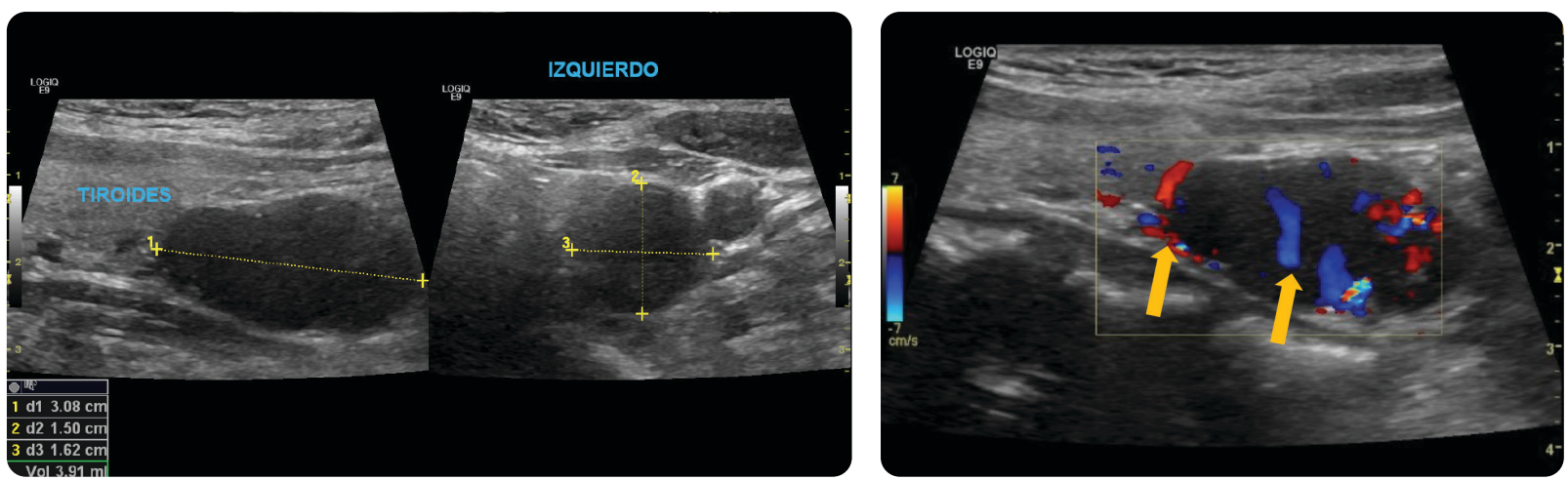

Figura 3. Ultrasonido de cuello. a) En ubicación anatómica de glándula paratiroidea inferior izquierda: lesión ovalada, sólida, hipoecoica, de bordes definidos. b) Ultrasonido Doppler color: vascularidad periférica y central sugerente de malignidad (flechas).

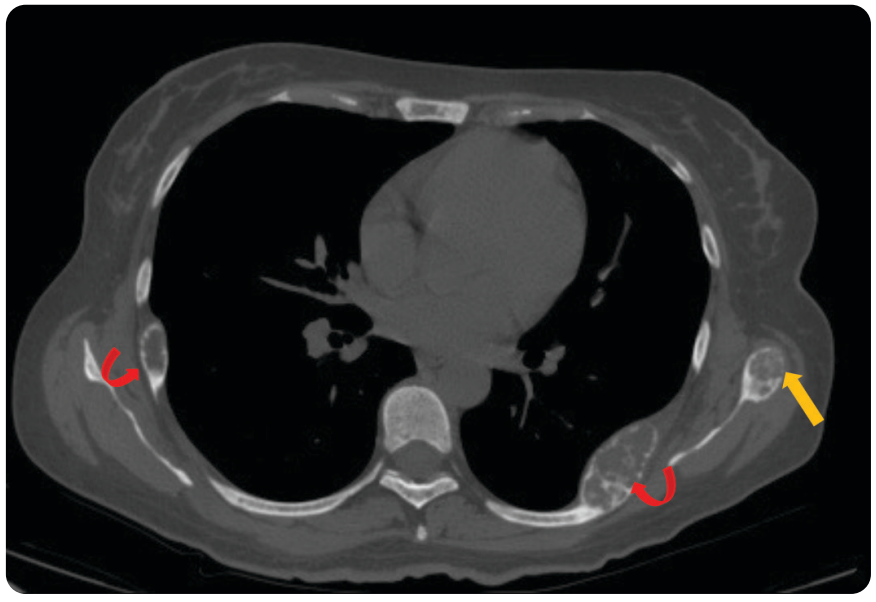

Figura 4. TC ventana ósea, corte axial. Se identifican en séptimo, octavo arco costal en segmento posterior y en borde lateral de escápula izquierda lesiones líticas que expanden la cortical, características de tumores pardos.

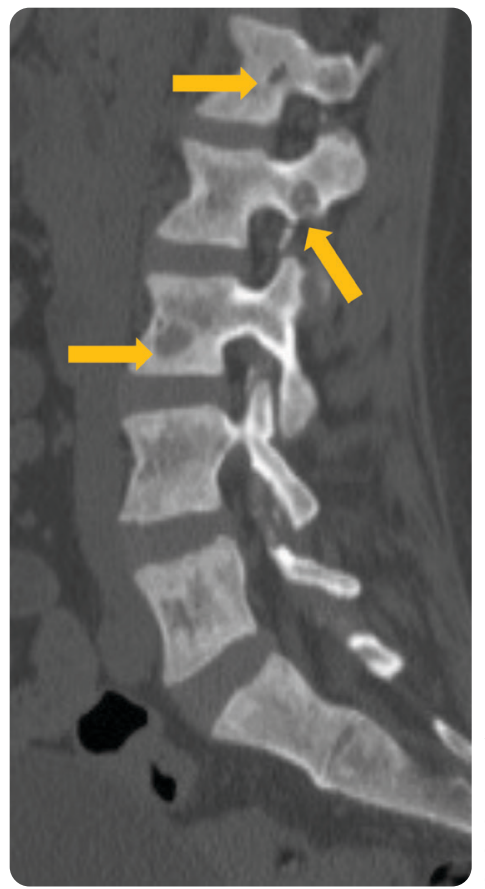

Figura 5. TC reconstrucción sagital de columna: lesiones líticas, ovaladas, de localización intramedular, que no provocan destrucción de la cortical de los cuerpos vertebrales de T12, L3 y en pedículo de L2.
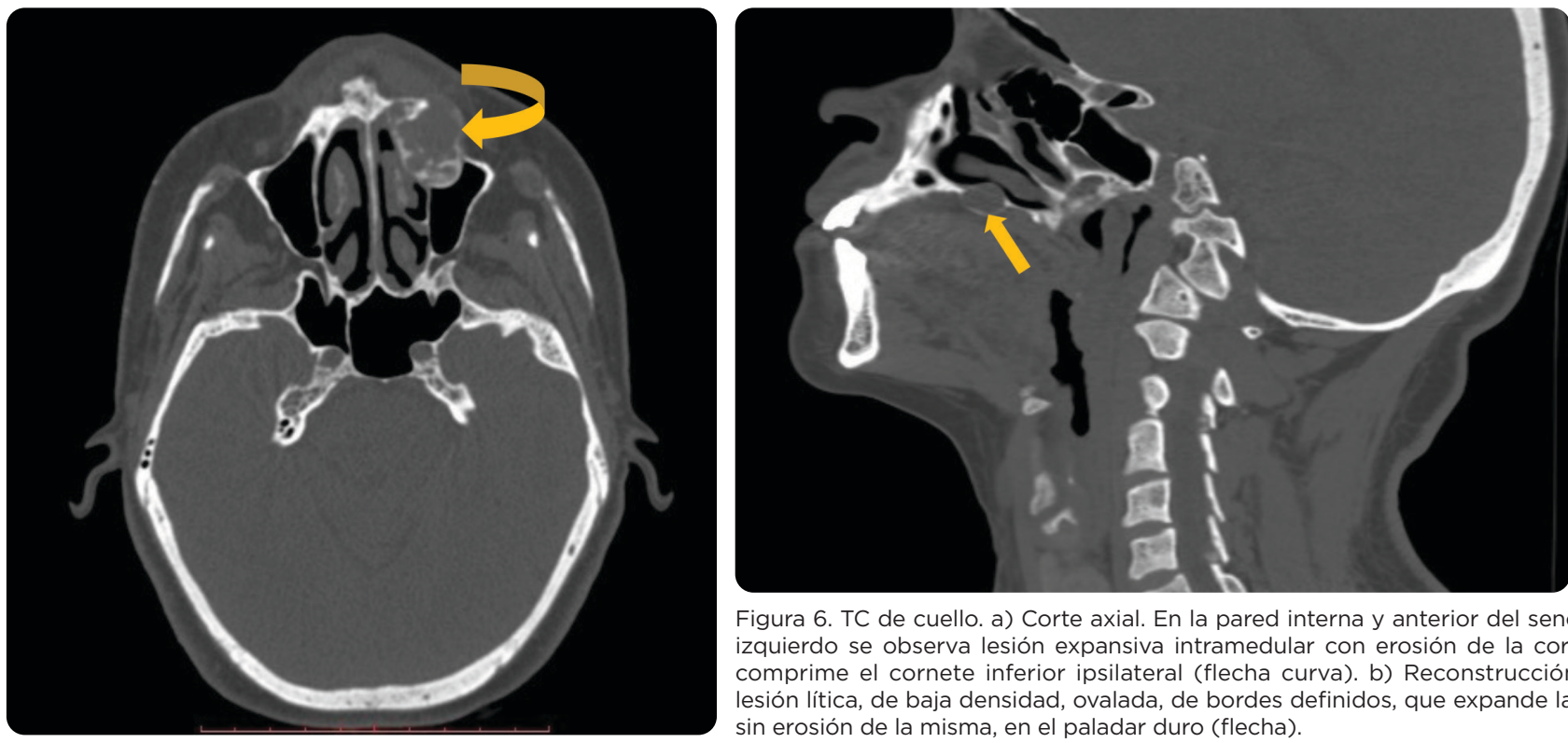

Figura 6. TC de cuello. a) Corte axial. En la pared interna y anterior del seno maxilar izquierdo se observa lesión expansiva intramedular con erosión de la cortical que comprime el cornete inferior ipsilateral (flecha curva). b) Reconstrucción sagita: lesión lítica, de baja densidad, ovalada, de bordes definidos, que expande la cortical, sin erosión de la misma, en el paladar duro (flecha). 


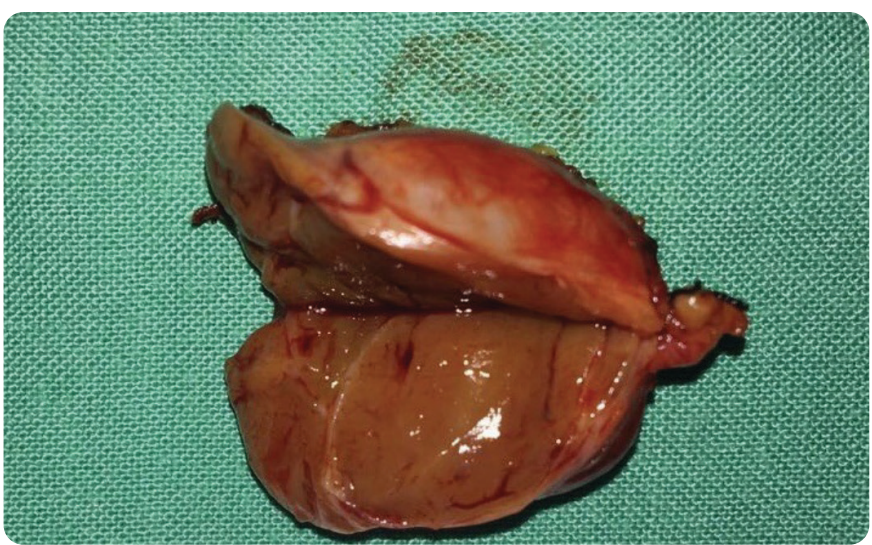

Figura 7. a) Masa paratiroidea inferior izquierda de superficie gris rosada, lisa, brillante, de $2,9 \times 1,5 \times 1 \mathrm{~cm}$ y pesa $8 \mathrm{~g}$. b) Corte histológico en el cual se evidencia infiltración de la cápsula, sobrepasándola y extendiéndose hacia el tejido peritiroideo, con infiltración del borde inferior y permeación vascular/linfática de los vasos capsulares.

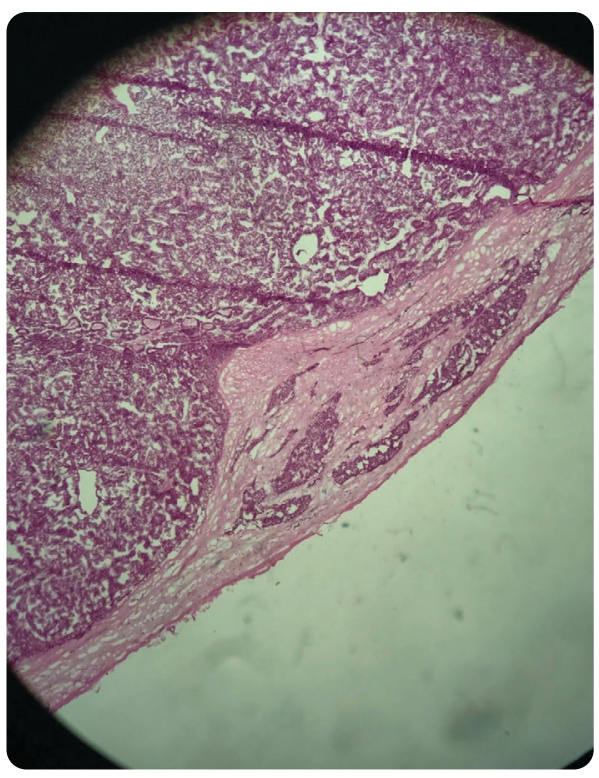

La mayoría de los tumores pardos se presentan como lesiones solitarias y en algunos casos raros, como lesiones múltiples. Los huesos comúnmente afectados son la pelvis, las costillas, los fémures, el húmero y otros huesos largos (25).

La ubicación en la mandíbula y maxilar es inusual, 4,5\%, aunque es más frecuente en la mandíbula que en el maxilar; es aún menos habitual en ambos huesos maxilares simultáneamente (7).

Nuestra paciente tenía múltiples lesiones óseas, así como en maxilar izquierdo, mandíbula, C5, C6, L3 y pedículo de L2, por lo cual fue necesario realizar diagnósticos diferenciales; inclusive, una única lesión en el palar duro, de la cual, no se encuentran casos descritos (figura 6b). Los criterios clínicos para la sospecha de neoplasia paratiroidea maligna según Obara et al., son: edad menor de 55 años; marcada hipercalcemia y aumento de paratohormona —más de 10 veces por encima del límite-; síntomas óseos graves —osteítis fibroquística en $40 \%$ a $70 \%$ de los casos-y síntomas renales — nefrocalcinosis, nefrolitiasis en $30 \%$ a $60 \%$ de los casos-; parálisis laríngea recurrente debido a la invasión tumoral; inflamación cervical palpable — rara en la enfermedad benigna- (14).

El hiperparatiroidismo primario es la causa más común de hipercalcemia y debe considerarse en cualquier persona con un nivel elevado de calcio en suero. Uno de los aspectos relevantes del tumor pardo en este caso es que representó la expresión primaria del hiperparatiroidismo primario, secundario a carcinoma de paratiroides, lo cual es infrecuente, debido a que en las últimas décadas la incorporación del calcio sérico en las pruebas de rutina de laboratorio detecta esta enfermedad en estadios asintomáticos o mínimamente sintomáticos (26).

Sin embargo, debido a la falta de accesibilidad a centros hospitalarios y a estudios seriados, la enfermedad progresa a múltiples tumores de localización difusa, incluyendo localizaciones infrecuentes. También se evidenciaron manifestaciones como debilidad, astenia y estreñimiento, las cuales se han descrito en la literatura en pacientes que cursan con la enfermedad (4). 
Debido a la lesión en el maxilar izquierdo y a las características histológicas comunes se hizo un diagnóstico diferencial con otras entidades que afectan al macizo facial, como el tumor de células gigantes, el quiste óseo aneurismático y el querubismo. Radiográficamente hay que diferenciarlo de las lesiones odontogénicas, como el ameloblastoma, los queratoquistes odontogénicos y los odontomas complejos (27).

La resección en bloque de un carcinoma paratiroideo primario es el tratamiento inicial de elección. Las complicaciones metabólicas relacionadas con la hipercalcemia se asocian con una mayor mortalidad. Incluso si se detecta metástasis o recurrencia, la resección agresiva del carcinoma paratiroideo metastásico es el tratamiento más efectivo para controlar la hipercalcemia y mejorar la supervivencia (28).

La enfermedad recurre en más del $50 \%$ de los pacientes. La resección quirúrgica es el modo primario de terapia para la recurrencia, así como paliación para el trastorno metabólico causado por hiperparatiroidismo. Las reoperaciones rara vez son curativas, y la quimioterapia y los tratamientos de radiación son ineficaces (29).

\section{Conclusiones}

El tumor pardo representa el estadio más avanzado de la enfermedad ósea asociada al hiperparatiroidismo. Cabe señalar que los tumores pardos son lesiones no neoplásicas, que no tienen potencial maligno, por lo que se consideran granulomas reparadores y sus principales diagnósticos diferenciales son metástasis, linfoma, el tumor de células gigantes, el quiste óseo aneurismático, querubismo, ameloblastoma, queratoquistes odontogénicos y los odontomas complejos.

Dentro de las principales características radiológicas en el hiperparatiroidismo se observan reabsorción subperióstica de la cortical ósea en múltiples localizaciones, osteopenia generalizada o yuxtaarticular y los tumores pardos. Los sitios de aparición más frecuente de este último son huesos largos, costillas, pelvis, maxilar, mandíbula, cráneo e incluso vértebras. En este caso se identificaron tanto en el esqueleto axial como en el apendicular.

El tratamiento inicial del tumor pardo consiste en la eliminación de la causa y en el control de la enfermedad metabólica, que en este caso consistió en la resección del carcinoma paratiroideo; esto favorece la normalización de los niveles hormonales y puede ser suficiente para estimular la mineralización y la progresiva desaparición de la lesión.

\section{Referencias}

1. Xie C, Tsakok M, Taylor N, Partington K. Imaging of brown tumours: a pictorial review. Insights Imag. 2019;10(1). doi: 10.1186/s13244-019-0757-Z.

2. Arias W, Ayala A, Pacheco F, Barzallo D. Tumor pardo multifocal como manifestación del hiperparatiroidismo primario por adenoma paratiroideo asociado a carcinoma papilar de tiroides. Rev Chil Cir. 2014;66(6):592-8. doi: 10.4067/s071840262014000600014

3. Madkhali T, Alhefdhi A, Chen H, Elfenbein D. Primary hyperparathyroidism. Turkish J Surg. 2016;32(1):58-66. doi: 10.5152/ucd.2015.3032.

4. Alfawareh M, Halawani M, Attia W, Almusrea K. Brown tumor of the cervical spines: A case report with literature review. Asian Spine J. 2015;9(1):110. doi: 10.4184/ asj.2015.9.1.110.

5. Kwon J, Kim E, Lee H, Moon H, Kwak J. Neck ultrasonography as preoperative localization of primary hyperparathyroidism with an additional role of detecting thyroid malignancy. European J Radiol. 2013;82(1):e17-e21. 10.1016/j.ejrad.2012.08.003.

6. McDonald D, Parman L, Speights V. Primary hyperparathyroidism due to parathyroid adenoma. RadioGraphics. 2005;25(3):829-34. doi: 10.1148/rg.253045042.

7. Mora-Escudero I, Gato-Díez A, Blázquez-Cabrera J, Lozano-Setien E, García-de-laTorre J. Tumores pardos pretibiales como manifestación inicial de un hiperparatiroidismo primario. Rev Clín Española. 2012;212(3):e15-e18. doi:10.1016/j.rce.2011.07.014.
8. Herrera A, Aranda P, Díaz J. Cáncer de paratiroides: revisión de literatura. Rev Española Enfermed Metaból Óseas. 2007;16(6):124-9. doi:10.1016/s1132-8460(07)73511-0.

9. Morán L, Moeinvaziri M, Fernández A, Sánchez R. Multiple brown tumors mistaken for bone metastases. Computed tomography imaging findings. Egyptian J Radiol Nucl Med. 2016;47(2):537-41. doi: 10.1016/j.ejrnm.2016.03.001

10. Rocha AL, Suazo LC, González PM, Lee ChK, Rossel DG. Hiperparatiroidismo primario y cáncer de paratiroides: Caso clínico. Rev Chil Cirugía. 2010;62(5). doi: 10.4067/s0718-40262010000500016.

11. Jakubowski J, Vélez I, McClure S. Brown tumor as a result of hyperparathyroidism in an end-stage renal disease patient. Case Reports Radiol. 2011;2011:1-3. doi: $10.1155 / 2011 / 415476$.

12. Parra Ramírez P, Lecumberri Santamaría B, Álvarez Escolá C, Pallardo Sánchez L. Hiperparatiroidismo primario con osteítis fibrosa quística simulando una neoplasia ósea maligna. Endocrinol Nutric. 2013;60(2):96-8. doi: 10.1016/j.endonu.2012.02.012.

13. Ferraro V, Sgaramella LI, Di Meo G, et al. Current concepts in parathyroid carcinoma: a single Centre experience. BMC Endocr Disord. 2019;19(46). https://doi.org/10.1186/ s12902-019-0368-1.

14. Fernandes J, Paiva C, Correia R, Polónia J, Moreira da Costa A. Parathyroid carcinoma: From a case report to a review of the literature. Inter J Surg Case Reports. 2018;42:214-7. doi: 10.1016/j.ijscr.2017.11.030.

15. Rosai JDR, Carcangiu ML, Frable WJ, Tallini G. Tumors of the thyroid and parathyroid glands. AFIP Atlas of Tumor Pathology. Silver Spring, Maryland: ARP Press; 2014.

16. Betea D, Bradwell A, Harvey T, Mead G, Schmidt-Gayk H, Ghaye B et al. Hormonal and biochemical normalization and tumor shrinkage induced by anti-parathyroid hormone immunotherapy in a patient with metastatic parathyroid carcinoma. J Clin Endocrinol Metabolism. 2004;89(7):3413-20. doi: 10.1210/jc.2003-031911

17. Erickson L, Mete O. Immunohistochemistry in diagnostic parathyroid pathology. Endocrine Pathol. 2018;29(2):113-29. doi: 10.1007/s12022-018-9527-6

18. Shi C, Guan H, Qi W, Ji J, Wu J, Yan F et al. Intrathyroidal parathyroid adenoma: Diagnostic pitfalls on fine-needle aspiration: Two case reports and literature review. Diagnostic Cytopathol. 2016;44(11):921-5. doi: 10.1002/dc.23528

19. Wong Y, Sharifah N, Tan G, Gill A, Ali S. Intrathyroidal oxyphilic parathyroid carcinoma: A potential diagnostic caveat in cytology? Diagnostic Cytopathol. 2016;44(8):68892. doi: $10.1002 / \mathrm{dc} .23493$.

20. Shane E. Parathyroid carcinoma. J Clin Endocrinol Metabolism. 2001;86(2):485-93. doi: $10.1210 /$ jcem. 86.2 .7207

21. García J, Álvarez Moro F, Bassa P, Soler M, Llinares E, Riera E. Detección de tumores pardos por hiperparatiroidismo secundario mediante PET/TC con 11C-colina. Rev Española Med Nuclear Imagen Molecular. 2016;35(3):209-10. doi: 10.1016/j. remn.2015.07.009

22. Insogna K. Primary hyperparathyroidism. New Engl J Med. 2018;379(11):1050-9. doi: 10.1056/nejmcp1714213.

23. Piciucchi S, Barone D, Gavelli G, Dubini A, Oboldi D, Matteuci F. Primary hyperparathyroidism: imaging to pathology. J Clin Imag Sci. 2012;2:59. doi: 10.4103/21567514.102053.

24. Park S, Kong G, Kwon Y, Park J. Pathologic fracture of the femur in brown tumor induced in parathyroid carcinoma: A Case Report. Hip Pelvis. 2016;28(3):173. doi: 10.5371/hp.2016.28.3.173.

25. Park Y, Yoon T, Park K, Ko J. Subchondral bone restoration of supra-acetabular brown tumor secondary to parathyroid carcinoma: A Case Report. Hip Pelvis. 2018;30(2):120. doi: $10.5371 / \mathrm{hp} .2018 .30 .2 .120$.

26. Marcocci C, Cetani F. Primary hyperparathyroidism. New Eng J Med 2011;365(25):2389-97. doi: 10.1056/nejmcp1106636.

27. Radulescu D, Chis B, Donca V, Münteanu V. Brown tumors of the femur and pelvis secondary to a parathyroid carcinoma: Report of one case. Rev Méd Chile. 2014;142(7):919-23. doi: 10.4067/s0034-98872014000700014.

28. Kim Y. Parathyroid carcinoma with lung metastasis in a thirteen-year-old girl. J Korean Surg Society. 2012;82(6):385. doi: 10.4174/jkss.2012.82.6.385.

29. Fortson J, Su R, Patel V, Lawrence G. Parathyroid carcinoma presenting with pathologic fracture: Case report and review of the literature. Head Neck. 2015;37(11):E139-E141. doi: 10.1002/hed.23965

\section{Correspondencia}

Silvia Lissett Espinoza

Res. Loma Linda Norte, Bloque 180, Apart 2.

11101

Tegucigalpa, Honduras

s.lissespinoza@gmail.com

Recibido para evaluación: 5 de febrero de 2020

Aceptado para publicación: 18 de mayo de 2020 